\title{
Technical Methodology to Evaluate the Decommissioning of the Contaminated Underground Structures Belonging to the VVR-S Nuclear Research Reactor
}

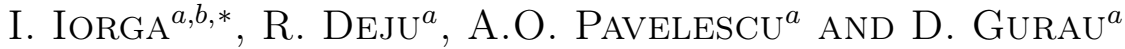

${ }^{a}$ Horia Hulubei National Institute of Physics and Nuclear Engineering (IFIN-HH),

P.O. Box MG-6, RO-077125, Magurele, Romania

${ }^{b}$ Faculty of Physics, University of Bucharest, P.O. Box MG-11, 077125, Bucharest-Magurele, Romania

Technical methodology to evaluate the decommissioning of the underground pipes connecting the $30 \mathrm{~m}^{3}$ buffer tank of liquid effluents belonging to the Nuclear Reactor VVR-S to the $300 \mathrm{~m}^{3}$ radioactive waste treatment station tanks from the IFIN-HH was made. Type and concentration of radionuclides found in irradiated materials with neutrons depend from nuclides, exposure duration to radiation, the energy and flux of incident neutrons. Internal and external contamination for the technology systems was caused by deposition inside the pipes and equipment of the particulate or soluble compounds circulated by the effluent, and the contamination leaked because of systems maintenance operations or management of radioactive waste. Important radionuclides in decommissioning depend primarily on the type of nuclear facility. For this research reactor in accordance with the approved decommissioning plan and radiological characterization, important radionuclides for underground structures are: $\mathrm{Am}^{241}, \mathrm{Cs}^{137}$, $\mathrm{Co}^{60}, \mathrm{Sr}^{90}-\mathrm{Y}^{90}$ and $\mathrm{Eu}^{152}$. For reactor, the inventory was calculated based on size, weight, irradiated components composition, analyzing trace elements, impurities, and integrated neutron flux and reactor operation history. Thus, the radioactive contents will result based on estimates associated with radiation doses which are then validated through on-site measurements. Internal contamination of irradiated components is estimated based on experimental measurements and correlation factors before a major radionuclide $\mathrm{Co}^{60}$. As results the total level of contamination $\left(\mathrm{Cs}^{137}\right.$ and $\left.\mathrm{Co}^{60}\right)$ measured during cutting operations was between $11 \mathrm{~Bq} / \mathrm{cm}^{2}$ and $75 \mathrm{~Bq} / \mathrm{cm}^{2}$. Beta gamma superficial contamination level of outer pipe is close to the background within the error measurements limits.
\end{abstract}

DOI: 10.12693/APhysPolA.134.311

PACS/topics: decommissioning, methodology, radioactive effluents, contamination

\section{Introduction}

The VVR-S nuclear research reactor, owned by Horia Hulubei - National Institute for Physics and Nuclear Engineering (IFIN-HH), was the first research reactor using the VVR-S type soviet design, built between 1955 and 1957. The role of the reactor was for research and radioisotope production. VVR-S means that it is a thermal neutrons reactor model S moderately cooled and reflected with distilled water, fueled with enriched uranium $10 \%$ in the beginning and $36 \%$ subsequently. The research reactor operated until 1997 and was permanently shut-down in 2002. During his life time, it was functional for a period of $113467 \mathrm{~h}$, including $2000 \mathrm{~h}$ at 3.0-3.5 MW power. The total power output up to 1997 was $9.59 \mathrm{GW} / \mathrm{d}$. It had a utilization factor of $65 \%$ (approximate 9510 effective days of operation) with an average of $1 \mathrm{MW}$ thermal power. The decommissioning of the reactor has started in 2010 and is planned to be finalized in 2020 [1]. Information on each nuclear facility design, construction and operation should be collected, organized and kept in good condition, later being essential in developing the decommissioning plan, especially if decommissioning is post-

*corresponding author; e-mail: johnny@nipne.ro poned times higher. Unfortunately not the same thing happened when nuclear research reactor VVR-S, which due to technical and political conditions of the time commissioners and operation has many gaps in history and documenting operating system. The preliminary radiological characterization was that led to the elaboration and approval of the decommissioning plan concentrated on installation itself without considering the case of underground explicit. So because the area for the ELI-NP construction was overlapping over the area of the transporting radioactive effluents pipes, these activities scheduled for Phase 3 of VVR-S nuclear reactor decommissioning were changed to be made in Phase 1.

\section{The underground structures description}

The underground structures were finally built between 1965 and 1967 when there was installed the transfer radioactive effluents pipe between nuclear research reactor $30 \mathrm{~m}^{3}$ radioactive effluents leakages pond and the two $300 \mathrm{~m}^{3}$ radioactive effluents storage ponds. After years 1975-1977 when the treatment plant was constructed these 2 ponds were transferred in this facility administration. Today here are collected radioactive effluents from all operators from IFIN-HH site [2].

In Fig. 1 there can be visualized the schematic of the underground radioactive effluents pipes from the IFINHH VVR-S Nuclear Research Reactor. 


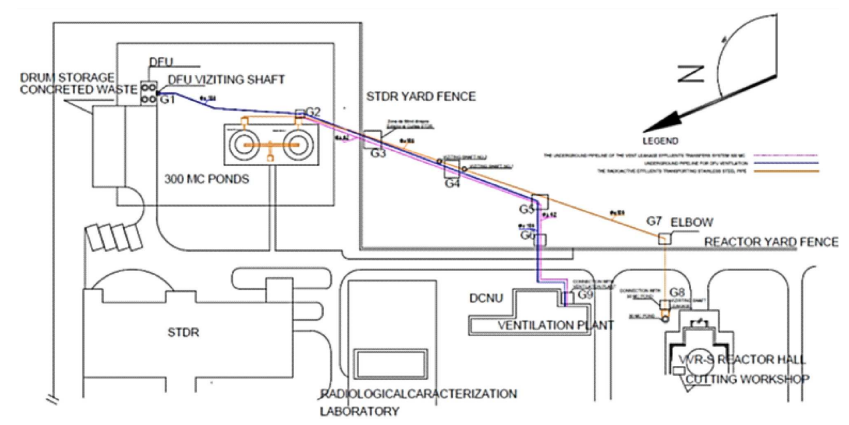

Fig. 1. The schematic of the underground radioactive effluents pipes from the IFIN-HH VVR-S Nuclear Research Reactor.

The $30 \mathrm{~m}^{3}$ radioactive effluents leakages pond was located near reactor hall. Radioactive effluents from the reactor are transferred to STDR through the pipeline, using compressed air, using pressures up to 3 atm. The pond is presently used for direct collection by free fall of radioactive liquid waste resulting from: primary circuit basin, the hot cells, the drainage system and the away from reactor (DCNU) radioactive ponds. The spent filters storage (DFU) was built between 1955 and 1957 for the storage of the solid radioactive waste. In conformity with the VVR-S reactor final security report (RFS) has not been used since 1979 [2]. Ventilation of the four storage cells was achieved by a carbon steel (OLC) pipe that made the connection between DFU and ventilator V4 from the reactor plant located near DCNU. Location DFU is apparent reference point G1. The $300 \mathrm{~m}^{3}$ radioactive effluents storage ponds are located inside the STDR courtyard (reference point G2). The stainless steel pipe for radioactive effluents transporting was emplaced in 1956. The outer diameter is $108 \mathrm{~mm}$ and the wall thickness is $5 \mathrm{~mm}$. After in situ identifying it was noted that this pipeline starts at a depth of $2.75 \mathrm{~m}$ from the reference point G2 (300 $\mathrm{m}^{3}$ ponds) up to a depth of $2.0 \mathrm{~m}$ in the visiting shaft no. 2, where it went down for $1.9 \mathrm{~m}$, made an L (see Fig. 3) and then went almost horizontally to the visiting shaft no. 1 at $6.50 \mathrm{~m}$ depth. It was protected between these two shafts by insertion into a carbon steel pipe with diameter of $200 \mathrm{~mm}$ and wall thickness of $3 \mathrm{~mm}$. From point G4 it went to route G4-G5-G7-G8. In the point $\mathrm{G} 7$ (depth $6 \mathrm{~m}$ ) the pipeline made an elbow shaped pound and from here climb the gentle slope to the $30 \mathrm{~m}^{3}$ radioactive effluents leakages pond where it reached a depth of $5.80 \mathrm{~m}$ (reference point G8). The underground pipeline of the vent leakage effluents transfers system was made from carbon steel with an outer diameter of $62 \mathrm{~mm}$ and a wall thickness of $5 \mathrm{~mm}$. During installation, the underground was protected with tar to prevent corrosion. The pipe was positioned at a depth of 1.5 to a maximum of $2.5 \mathrm{~m}$ and was parallel and adjacent to pipelines for DFU ventilation. This metal vent pipe was connected to the central ventilation fan V4-reactor which provides a flow of $1500 \mathrm{~m}^{3} / \mathrm{h}$ and reaches $300 \mathrm{~m}^{3}$ tanks. It has no other protection around it. Underground pipeline for DFU ventilation was made from carbon steel with an outer diameter of $108 \mathrm{~mm}$ and a wall thickness of $5 \mathrm{~mm}$. The pipe is positioned at a depth of $1.5 \mathrm{~m}$ to a maximum of $2.5 \mathrm{~m}$ and was parallel and adjacent to pipeline of the vent leakage effluents transfers system. It was connected to V4 in the ventilation building of the reactor plant. Since DFU was no longer used since 1979 so the ventilation was no longer necessary. In this respect, according to the RFS changes were made: shielding pipe in visiting shaft (reference point G1) and valve area in 1979. Note: in reference point G5 both ventilation pipes intersected and were supported by a metal rod with a diameter of $50 \mathrm{~mm}$. The visiting shafts no. 1 and no. 2 were made from concrete tubes with an outer diameter of $1.1 \mathrm{~m}$ and wall thickness of $10 \mathrm{~cm}$. Visiting shafts covers had four stacked lids with outer diameter of $110 \mathrm{~cm}$ and wall thickness of $10 \mathrm{~cm}$, and eight stacked inner lids with an outer diameter of $100 \mathrm{~cm}$ wall thickness of $10 \mathrm{~cm}$. They also raised $80 \mathrm{~cm}$ above the ground. The visiting shaft no. 1 had a height of $6.70 \mathrm{~m}$ (see Fig. 3) and the visiting shaft no. 2 had a height of $4 \mathrm{~m}$ (see Fig. 2).
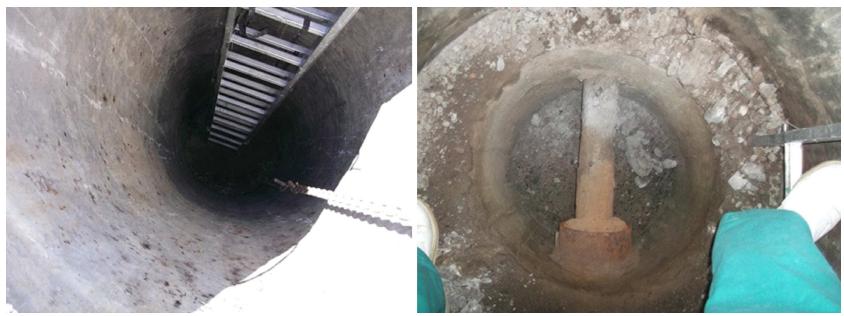

Fig. 2. The visiting shaft no. 2 .
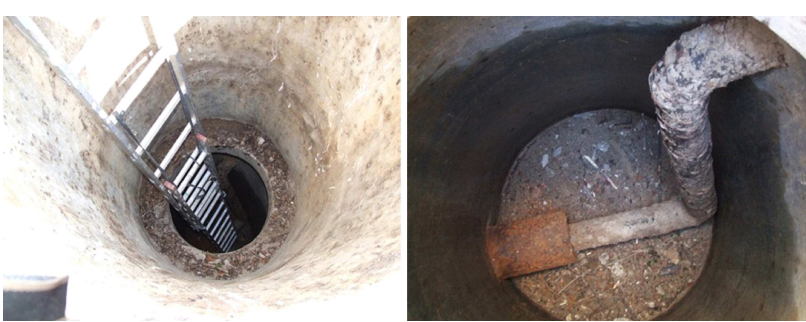

Fig. 3. The visiting shaft no. 1.

\section{Decommissioning methodology}

The most important factors in the elaboration and execution of decommissioning are the following: (i) Estimation and verification of radioactive inventory for both radioactivity induced by neutron activation and for radioactive substances deposited on the internal and external surfaces of technological systems. (ii) Correct inventory estimates of the type and amount of radionuclides in the nuclear facility directly affect the decommissioning approach by establishing the start time and the need for delays in operations. (iii) This information is input for the designer to determine decontamination, protection, remote, packing and intermediate storage needs as 
well as potential exposures to irradiation. (iv) The inventory should include the detailed description on individual components: radioactive content, physical and chemical form, volume and weight. It should be continually updated with decommissioning progress. In case of contamination with short life radionuclides, by delaying the transition to next stage of activities, natural disintegration will significantly reduce the total amount of waste as well as the doses of operator exposure [3-5]. The type and concentration of radionuclides found in neutron irradiated materials depend on the initial nuclides in the material, the duration of irradiation, the energy and flux of the incident neutrons. The internal and external contamination of the technological systems is caused by the deposition of particles or soluble compounds in the pipelines and equipment's process effluent and contamination caused by leakage of technological systems and radioactive waste management or maintenance operations. For this research nuclear reactor, the inventory is calculated based on the dimensions, weights, composition of the irradiated components by analyzing the tracer elements, impurities, integrated neutron flux, and the history of reactor operation. From the radioactive content, based on codes, the associated radiation doses are estimated, which are then validated by spot measurements. Internal contamination of non-irradiated components is estimated based on experimental measurements and correlation factors against a major radionuclide like $\mathrm{Co}^{60}$ and $\mathrm{Cs}^{137}[6]$. The calculated values should be tested experimentally following a rigorous sampling program and measurement.

Prior to the commencement of decommissioning activities, an inventory of toxic and hazardous materials such as beryllium, as well as pyrophoric, flammable and toxic chemicals should be developed. These materials may or may not be radioactive and directly affect the techniques and cost of decommissioning.

Taking into account the fact that the underground structures are connected to the $300 \mathrm{~m}^{3}$ basins for radioactive effluent storage of the radioactive waste treatment plant (STDR), additional protective measures have to be taken, especially since during the preliminary assessment there was a significant increase in the dose rate due to wastes in the STDR perimeter. Also, the radon content increased [7] with the depth at which the excavation was performed - maximum around 7.5 to $8.5 \mathrm{~m}$.

Once the decommissioning has begun, the resulting waste must be monitored and characterized with a much higher accuracy than the calculated initial estimates. The objective of this characterization is to ensure the handling, conditioning and storage of waste in a safe and economical manner. The program must meet: (i) segregation of waste into activated, inactive and exempted to reduce the costs of its management, (ii) the proper management of radioactive waste is in line with the type and characteristics of the waste, and (iii) the final radiological characterization of the site [3-5].

\section{Methods and equipment used for waste characterization}

Waste management involves the general treatment, conditioning, storage, transport and storage methodology. For the determination of methods and technologies it is necessary to estimate the volume of waste classifying all systems and structures, masses and volumes of solid incinerable waste, non-compacts, volumes of liquid, gaseous and aerosol waste. The choice of treatment and conditioning technology depends on physical, chemical, radiological properties, the existence of processing facilities, handling and transport facilities and economic considerations.

Decontamination in the decommissioning process is used to reduce the radiation fields by removing activation or fission products contained in precipitation deposits, oxidation films or dust deposits in installations. Another objective of decontamination is the reuse or recycling of materials and the fulfillment of storage requirements. Decontamination methods are generally those used in the nuclear field but are adapted to each plant to achieve maximum efficiency.

This adaptation includes a large-scale experimental sampling program and laboratory experiments to ultimately decide between a high-cost decontamination and a more shallow decontamination with low direct costs but with the cost of waste. In choosing the application specific decontamination process, account is taken first of all of the parameters that influence the decontamination factors: (i) type of installation (reactor, reprocessing, waste treatment, etc.) — in our case the underground structures are closely related to the operation history of the reactor, (ii) history of facility operation, (iii) types of decontaminated materials (OLC, stainless steel, concrete), (iv) type of surface (porous, rusty, painted, etc.), (v) type of contaminant (oxides, deposits, dust, gas, liquid, etc.), (vi) composition of the contaminant (activation products, fission, etc.), (vii) internal or external contamination - only contamination on the inner wall of the pipeline has been revealed, (viii) decontamination factors required - depending on the levels required for release in accordance with radiological safety standards (normative approved by regulatory body), (ix) destination of decontaminated components (reuse, storage for waste treatment), (x) the required application time, (xi) proven process efficiency - the process was very efficient, and (xii) type of decontaminated components (pipes, tanks, concrete etc.) [1, 8-12].

Other factors that are important in choosing the decontamination process, although they do not influence the decontamination factors are: (i) availability, cost and complexity of decontamination equipment, (ii) conditional generation of secondary waste, (iii) doses received by staff and the public from decontamination process, (iv) social, security and environmental issues, (v) availability of qualified staff, (vi) the degree of decontamination required by decommissioning conditions, 
(vii) degree of modification of the installation (isolation of systems, closings, ventilation, etc.), (viii) the value of materials that can be recycled or reused against the cost of storage $[1,8-12]$.

The main decontamination techniques used are the chemical ones, which use a wide variety of reagent mixtures, mechanical ones and others. The practical realization of the decommissioning of the underground structures involves the segmentation of metallic objects and the demolition of concrete structures. Thickness of the walls of the metal components to be cut: $5 \mathrm{~mm}$. Diameters: $62 \mathrm{~mm}$ ventilation pipes, $108 \mathrm{~mm}$ ventilation and radioactive effluent transport pipes, and $200 \mathrm{~mm}$ protective pipe from the inside of the visiting shaft. The materials used for the construction of underground structures are mainly carbon steel stainless steel and concrete.

The following techniques are used to segment ponds and internal structures: (i) The electric arc saw, it is a metal less toothbrush that cuts without direct physical contact. Cutting is achieved by maintaining an electric arc between the disc and the material. The disc may be steel or copper and has a rotational speed of 300$1800 \mathrm{rpm}$. The disc rotation cools and trains melted metal droplets. Cutting depth is limited by the diameter of the disc, for a diameter of $90 \mathrm{~cm}$ cut $30 \mathrm{~cm}$ walls. The electric arc saw can be used in air or under water. (ii) Plasma burner that cuts through the direct action of an electric arc set in a gas stream (argon) at a temperature of $10,000-24,000^{\circ} \mathrm{C}$. The maximum cutting depth is $17 \mathrm{~cm}$. The plasma stream, which consists of positive ions and free electrons, is ejected at high speed and in combination with the electric arc melts the metal to the contact area and expels it from the cut. The device operates in air and water, has a good cutting speed, but generates large amounts of particles, gases and aerosols to be captured. (iii) Oxyacetylene cutting is the one normally used with oxygen and a combustible gas (propane, hydrogen). When the metal to be cut reaches $800^{\circ} \mathrm{C}$, exothermic oxidation occurs, but only for iron components. For stainless steel, aluminum and other non-ferrous or high alloyed alloys, the method has problems be applied due to the formation of refractory oxides like $\mathrm{Al}_{2} \mathrm{O}_{3}, \mathrm{Cr}_{2} \mathrm{O}_{3}$ or $\mathrm{NiO}$. (iv) The thermite lance is an iron pipe with a compact mixture of steel, aluminum and magnesium powders, which burns in a stream of oxygen reaching a temperature of $2250^{\circ} \mathrm{C}$ in water and $5500^{\circ} \mathrm{C}$ in air. The typical lance is $3 \mathrm{~m}$ long and $6-10 \mathrm{~mm}$ in diameter. (v) Cutting with explosives involves a special explosion-controlled technique and is especially used for objects with complicated geometry - not used on the underground structures. (vi) Guillotines or scissors are commonly used industrial tools for any metal and offer 2 advantages: reduce the risk of fire and contamination by aerosols or particles, not generating gas or smoke. It is especially suitable for pipes with a diameter of up to $36 \mathrm{~cm}$. (vii) Cutting with abrasive discs is also a current technique, but it generates sparks and spreads particles driven by the disc. (viii) Circular cutting with a cutter disk that moves to the outside of the object surface (usually a pipe). You can cut pipes with thicknesses of $7 \mathrm{~cm}$ and diameters of $6 \mathrm{~m}$. On one pass the depth can reach $2 \mathrm{~cm}$ in OLC. Continuous lubrication prevents contamination dispersion. Almost all decommissioning operations require total demolition or surface decontamination of concrete structures [1, 8-12].

Difficulties are given by possible intense radiation fields and the potential spill of gas, dust and larger particles resulting from cutting dismantling and demolition. For wet demolition techniques there is the possibility of liquid leakage, which can only be decontaminated by destructive methods due to the porosity of the concrete. Even the demolition of uncontaminated concrete structures is difficult because of the high volumes and the steel used for reinforcement.

\section{Technical measures to ensure the decommissioning}

The technical conditions that make operations condition economically and securely must be ensured: (i) Storage of operational fluids such as lubricants, hydraulic oil, other radioactive or non-radioactive organic solvents that are hazardous and requires special storage conditions has not looked at the radioactive effluents found on the pipes to be analyzed and may be dangerous. (ii) Build additional or modified access and stripping areas for the conditions of specific decommissioning activities. Expansion of capacity or changes may require the installation of showers, the addition of monitoring instrumentation, the establishment of new routes for materials and personnel, new openings. The access route is very important. (iii) Normal ventilation must be in most cases modified in accordance with the new requirements, such as rearrangement of pipes and valves, supplementation of extraction fans and filters, provision of portable ventilation units. Finally, an assessment of the airflow across the system and the pressure differences has to be made. (iv) Additional containment barriers may be required in certain areas, made of plastic foil on a metal frame. They should be kept at a slight depression to prevent contamination spreading and the air flow must be tested before commissioning. For small volumes plastic bags with gloves can be used (in the case of pipe cuts with radioactive leakages). (v) Waste management, for example: the collection, characterization, handling, treatment, conditioning of large volumes of waste requires sufficient space and specific facilities. The chosen spaces must provide minimal interference with the actual decommissioning activities. Particularly a small radiant background space intended for radiometric measurements for each waste package must be provided. (vi) Build temporary storage areas for local storage of contaminated components and equipment prior to processing. In some cases shielding means must be provided. Other spaces must be provided for non-radioactive components, equipment and materials, as well as for the storage of consumable 
equipment and materials. (vii) The transport of waste involves the storage of large volumes of waste of all categories, for which must be determined the means and the transport containers, the routes and the time allocated. (viii) Means of decontamination and necessary spaces, as well as necessary resources (water, electricity, etc.). Resulting waste must be transferred for specific category processing. (ix) Radiological monitoring was provided for (i) environment (internal and external), (ii) personnel (fixed individual monitors and portable instrumentation), (iii) operational on different workspaces, area monitors, (iv) effluents and aerosol monitors, (v) waste (contamination, dose). ( $\mathrm{x}$ ) Drainage and drying systems by adapting existing ones such as compressed air, ventilation, vacuum. (xi) Prepare disassembly areas where large components or equipment are transferred for cutting and packaging. The area has been selected in the vicinity of the decommissioned system and ventilation, screens, confinement barriers must be provided. (xii) Distilled or deionized water to simplify management, decontamination and secondary waste. (xiii) Prepare respiratory masks to avoid potentially radioactive aerosols from cutting jets. (xiv) Light and additional communications from the original ones, as well as in case of decommissioning circuits. (xv) Electricity supply according to the working areas, the provision of temporary feeding systems, with their clear marking prevents the functional state. (xvi) Lifting devices (normal and auxiliary) inspected and certified for the required loads. (xvii) Viewing systems for spaces where remote-controlled equipment will be deployed. These can include TV, endoscopic circuits, etc. (xviii) Portable shields for lowering operator doses for intense radiation fields. (xix) Simulation stands for staff specialization and equipment verification before use. ( $\mathrm{xx}$ ) Fire protection tools, smoke detectors, alarms, interference capability specific to decommissioning activities. (xxi) Infrastructure support such as offices, dining room, passenger transport, telephones, security and control, medical services [1, 8-12].

The controlled working area must be delimited by physical means (ropes, panels, barriers) marked by signs of radiation hazard. In the area, at least one intermittent red light warning system will operate during the exposure. The boundary of the controlled area is verified by direct measurements. The controlled area is delimited and isolated at the limit at which the dose rate has a maximum value of $60 \mu \mathrm{Sv} / \mathrm{h}$.

\section{Result and discussion}

These underground systems and pipes was planned to be decommissioned in the stage 3 of the VVR-S nuclear reactor decommissioning project. Due to the preparatory activities (sitting, authorization and building) for the European Light Infrastructure - Nuclear Physics Facility (ELI-NP), it was necessary to remove the underground pipes. So these activities, especially phase 1 (reference points $\mathrm{G} 4 \div \mathrm{G} 7$ ) for underground pipes decommission, was performed in the end of stage 1 of the reactor decommissioning.
From operational history we assess that the radioactive effluents were discharged to $30 \mathrm{~m}^{3}$ pond from the primary circuit. If we take in consideration the time until the decommissioning after the permanent shutdown in 1997 (almost 19 years) we consider that possible radionuclides that can contaminate/activate the pipes are $\mathrm{Am}^{241}, \mathrm{Sr}^{90}-\mathrm{Y}^{90}, \mathrm{Co}^{60}, \mathrm{Cs}^{137}$ and $\mathrm{Eu}^{152}$. The entire pipe decommissioning activities were performed taking into account strict radiation protection measures, industrial safety, risk management and nuclear safety culture. The ALARA principle for maintaining the radiation protection exposure as low as is reasonable achievable was specifically implied. For the optimization of protection principle two guiding lines were observed: (i) Implementation of a predictive approach for limiting the assumed risks and (ii) Dose limits conforming was not considered sufficient, therefore radiation protection had been optimized taking into account the equipment, processes, and work management. The activity was carried out in three phases with duration of 6 weeks.

\subsection{Preliminary characterization phase}

It was carried out on in situ evaluation phase to acquire information for determining initial condition for protection of the workers and the environment. The obtained results for soil sample measurements have shown no contaminations for initial condition of the environment in exterior of the pipes. General radionuclides found by spectrometric measurements were: (i) $\mathrm{Ac}^{228}(0.036 \mathrm{~Bq} / \mathrm{g}$ $\div 0.040 \mathrm{~Bq} / \mathrm{g}$ ), (ii) $\mathrm{K}^{40}(0.35 \mathrm{~Bq} / \mathrm{g} \div 0.66 \mathrm{~Bq} / \mathrm{g})$, (iii) $\mathrm{Cs}^{137}(0.005 \mathrm{~Bq} / \mathrm{g} \div 0.026 \mathrm{~Bq} / \mathrm{g})$, (iv) $\mathrm{Co}^{60}(0.006 \mathrm{~Bq} / \mathrm{g}$ $\div 0.032 \mathrm{~Bq} / \mathrm{g})$, (v) $\mathrm{Pb}^{212}(0.046 \mathrm{~Bq} / \mathrm{g} \div 0.047 \mathrm{~Bq} / \mathrm{g})$, (vi) $\mathrm{Pb}^{214}(0.024 \mathrm{~Bq} / \mathrm{g} \div 0.054 \mathrm{~Bq} / \mathrm{g})$, (vii) $\mathrm{Bi}^{214}(0.020 \mathrm{~Bq} / \mathrm{g}$ $\div 0.063 \mathrm{~Bq} / \mathrm{g}$ ), and (ix) $\mathrm{Tl}^{208}(0.017 \mathrm{~Bq} / \mathrm{g} \div 0.018 \mathrm{~Bq} / \mathrm{g})$.

A simulation of assumed interior dose rate was made using MicroShield code to evaluate the potential risk of taking smear samples from the pipes interior. Initial condition was obtained from security safety report of the reactor (RFS) — wall thickness $4 \mathrm{~mm}$ and exterior dose rate measurement near the pipes surface. Results showed that the dose rate will be 4 times external dose. After insertion and taking in account the necessary radioprotection measures the revealed dose rate was 5 times greater and the thinness of the pipes was $5 \mathrm{~mm}$.

\subsection{Waste characterization and treatment phase}

There was carried out during pipes dismantling and was aimed to demonstrate the level of waste contamination and the proper execution of the pipes cutting. For this purpose every piece of the pipes was characterized and as well all cutting debris and other effluents leakages were sampled and characterized as well. The contaminated samples are the following: (i) mixture from pipes cutting points $\left(\mathrm{Cs}^{137}: 0.30 \mathrm{~Bq} / \mathrm{g} \div 23.89 \mathrm{~Bq} / \mathrm{g}\right.$, $\mathrm{Co}^{60}: 0.03 \mathrm{~Bq} / \mathrm{g} \div 0.13 \mathrm{~Bq} / \mathrm{g}$ ) and (ii) smears in cutting points for pipes emplacement evacuation $\left(\mathrm{Cs}^{137}\right.$ : $0.910 \mathrm{~Bq} / \mathrm{cm}^{2} \div 25.97 \mathrm{~Bq} / \mathrm{cm}^{2}, \mathrm{Co}^{60} 0.006 \mathrm{~Bq} / \mathrm{cm}^{2}$ $\left.\div 0.135 \mathrm{~Bq} / \mathrm{cm}^{2}\right)$. Total contamination level for $\mathrm{Cs}^{137}$ 
and $\mathrm{Co}^{60}$ during the pipes cutting operations for packaging was between $11 \mathrm{~Bq} / \mathrm{cm}^{2}$ and $75 \mathrm{~Bq} / \mathrm{cm}^{2}$ and the dose rate at $10 \mathrm{~cm}$ from the pipe exterior varied between $0.16 \mu \mathrm{Sv} / \mathrm{h}$ and $0.44 \mu \mathrm{Sv} / \mathrm{h}$.

In Fig. 4 there is presented the dose rate dependence with location of the pipes, using indirect measurement of beta-gamma contamination by sampling smears. This graph gives us potential to monitor the spread of contamination inside the pipes.

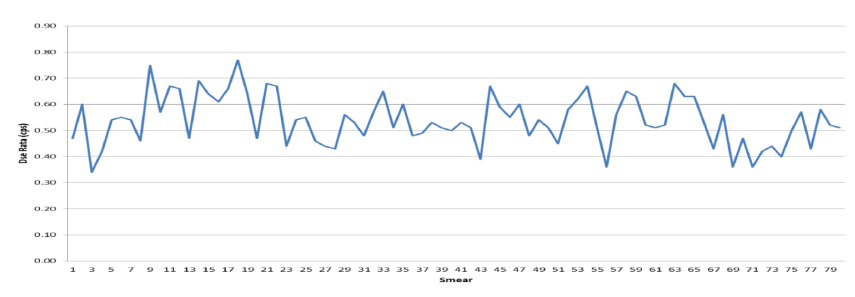

Fig. 4. Dose rate dependence with location of the pipes, using indirect measurement of beta-gamma contamination by sampling smears.
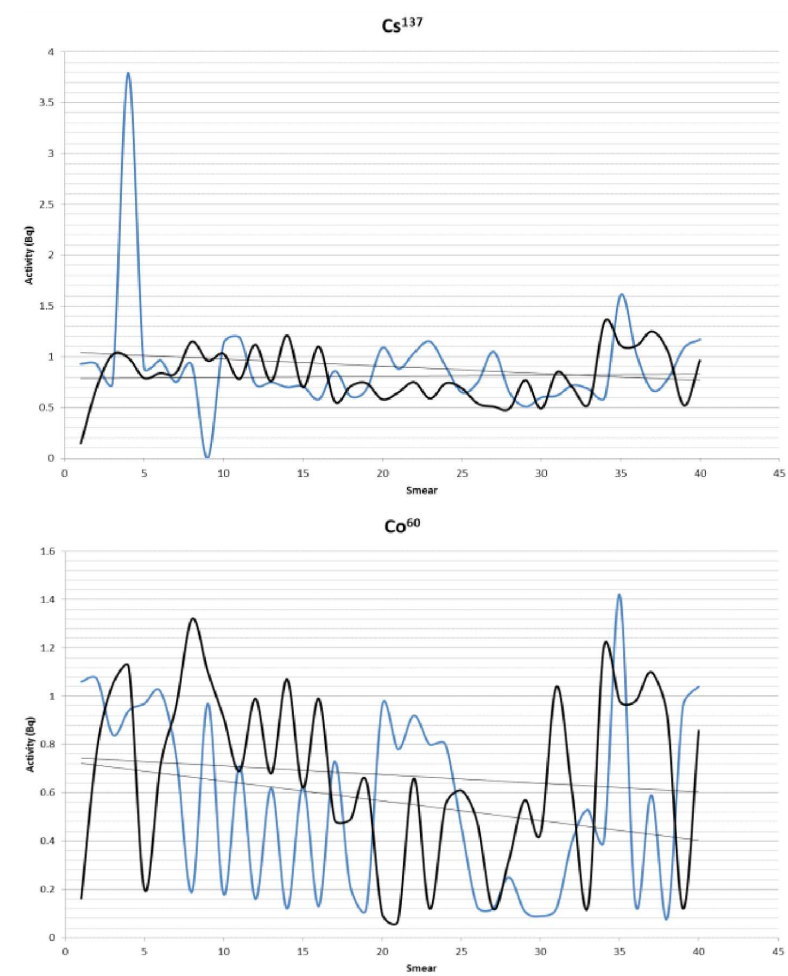

Fig. 5. Activity dependence for $\mathrm{Cs}^{137}$ and $\mathrm{Co}^{60}$ with location of the pipes.

In Fig. 5 is presented the activity dependence for $\mathrm{Cs}^{137}$ and $\mathrm{Co}^{60}$ with location of the pipes, using gamma spectrometric analysis to determine the specific activity of the samples. This graph gives us potential to monitor and discover increasing steps in $\mathrm{Cs}^{137}$ contamination activation especially near L shape point of the radioactive effluents transport pipe. The blue and the black are two separate sets of samples. We observe the double increased in contamination at probe 35 corresponding with L shape on the pipe. We have a relative low possible contamination of $\mathrm{Co}^{60}$ inside of the radioactive effluents transport pipe.

In Fig. 6 there is presented the activity dependence for $\mathrm{Cs}^{137}$ and $\mathrm{Co}^{60}$ with cutting location of the pipes, using gamma spectrometric analysis to determine the specific activity of the debris samples. These cuttings were made in the key points where we need to demonstrate the control of spread of the contamination. We have increased values around narrow areas, change of shape and close to the effluents storage ponds.

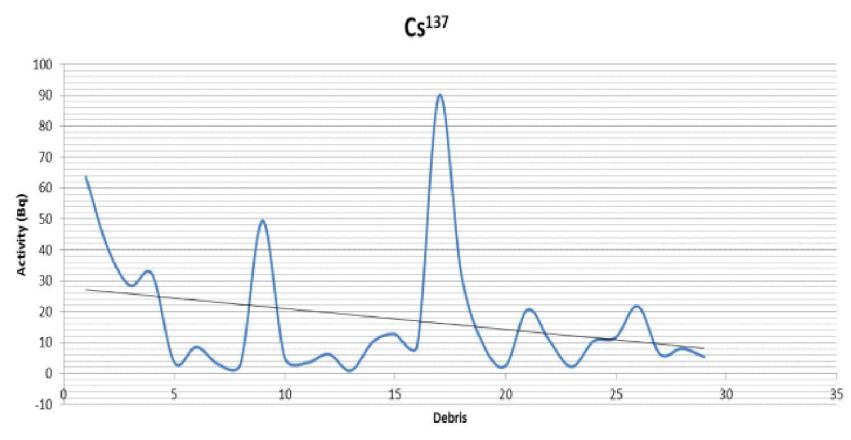

$\mathrm{Co}^{60}$

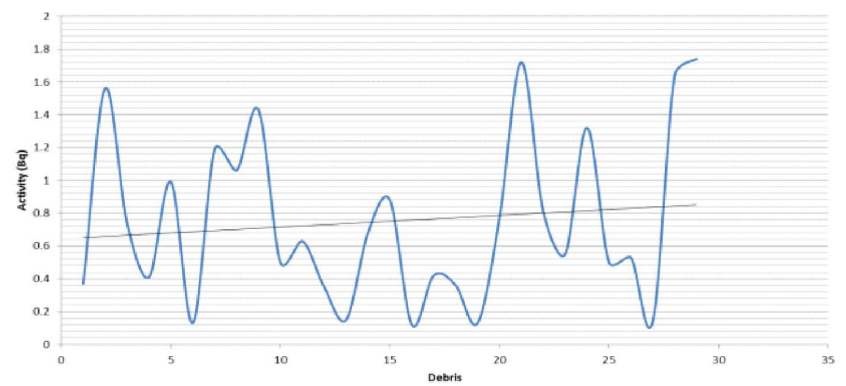

Fig. 6. Activity dependence for $\mathrm{Cs}^{137}$ and $\mathrm{Co}^{60}$ with cutting location of the pipes.

\subsection{Clearance phase}

It was carried out after all waste was evacuated from emplacement and was aimed to demonstrate that the environment was clean after the finalization of the pipes decommissioning. In Fig. 7 is presented the activity dependence for $\mathrm{Cs}^{137}$ and $\mathrm{Co}^{60}$ with sampling soil location, using gamma spectrometric analysis to determine the specific activity of the soil samples.

\section{Conclusion}

The waste characterization was carried out during pipes decommissioning and was aimed to demonstrate the level of waste contamination and the proper execution of the pipes cutting. For this purpose every piece of the pipes was characterized and the cutting debris and other effluents leakages were sampled and characterized as well.

$\mathrm{Am}^{241}$ was washed and transported by radioactive effluents to the $300 \mathrm{~m}^{3}$ ponds. 


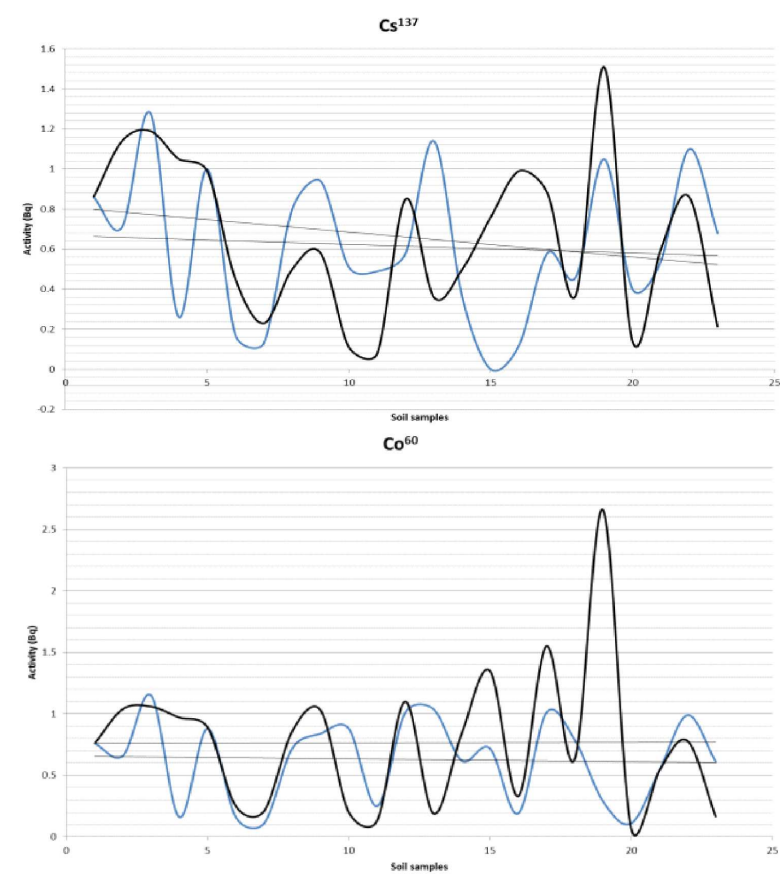

Fig. 7. Activity dependence for $\mathrm{Cs}^{137}$ and $\mathrm{Co}^{60}$ with sampling soil location.

$\mathrm{Sr}^{90}-\mathrm{Y}^{90}$ can be correlated with $2 \times 10 \%$ from $\mathrm{Cs}^{137}$ and was located majority around $\mathrm{L}$ shape place of the pipe. This means $0.06 \div 4.78 \mathrm{~Bq} / \mathrm{g}$.

$\mathrm{Eu}^{152}$ was not highlighted in the pipes, now we know that this radionuclide remain predominantly in the reactor vessels.

As a result of this approach, the decommissioning activities of the underground radioactive effluents pipe structures from the IFIN-HH VVR-S Research Reactor were successfully accomplished in a short time with minimal expenses, as well as without any environmental incidents, damages to equipment and injuries to working personnel and general public.

\section{Acknowledgments}

The paper is a part of the research activities done within the Decommissioning Project of the IFIN-HH VVR-S Nuclear Research Reactor.

\section{References}

[1] M. Dragusin, V. Copaciu, V. Popa, C. Dragolici, I. Iorga, R. Deju, C. Mustata, C. Tuca, I. Mincu, Decommissioning Plan of the VVR-S Research Reactor, ROM 04 029/2003, applicable revision.

[2] VVR-S RFS Reactor - VVR-S - Reactor Final Security Report, ISPE, Bucharest 1972.

[3] M. Dragusin, A.O. Pavelescu, I. Iorga, Nucl. Technol. Radiat. Protect. 26, 84 (2011).

[4] IAEA Nuclear Energy Series No. NW-G-2.1, Policies and Strategies for the Decommissioning of Nuclear and Radiological Facilities, International Atomic Energy Agency, Vienna 2011, ISBN:978-92-0-116910-5.

[5] Technical Reports Series No. 446, Decommissioning of Research Reactors: Evolution, State of the Art, Open Issues, International Atomic Energy Agency Vienna 2006, ISBN: 92-0-112605-0.

[6] IAEA Nuclear Energy Series No. NW-T-1.18, Determination and Use of Scaling Factors for Waste Characterization in Nuclear Power Plants, International Atomic Energy Agency, Vienna 2009, ISBN: 978-920-110808-1.

[7] Study Reports on Environmental Impact Assessment for Decommissioning of the Nuclear Research Reactor $V V R-S$ Magurele and upgrading STDR and DNDR, 2003-2007.

[8] M.F. Bodin, M.J.C. Saublet, M.R. Pech, Removal of underground piping decommissioning of buried, radiation-contaminated pipes, Procedure used at The La Hague Spent Fuel Reprocessing Plant, France 1991.

[9] Transportation Emergency Preparedness Program TEPP Planning Product Model Procedure for Radioactive Material or Multiple Hazardous Materials Decontamination, Prepared for the Department of Energy Office of Transportation and Emergency Management, Department of Energy United States of America, 2007.

[10] L.O. Waggoner, J.E. Kurtz, Dose Reduction Techniques, HNF 5691 FP Revision 0, Fluor Daniel, Hanford 2000

[11] Decommissioning of Underground Structures, Systems and Components, TRS-439, 2006.

[12] Strategy and Methodology for Radioactive Waste Characterization, IAEA-TECDOC-1537, 2007, ISBN:92-0-104405-4. 